\title{
TUMOR OVÁRICO, CÉLULAS DE LA GRANULOMATOSA JUVENIL. A PROPÓSITO DE UN CASO. HOSPITAL INFANTIL DOCTOR ROBERT REID CABRAL (HIRRC), REPÚBLICA DOMINICANA
}

\author{
Ovarian tumor, cells of the granulomatosa juvenille. About a case. \\ (Presentation of case), Robert Reid Cabral Children's Hospital, \\ Dominican Republic
}

\author{
Elvyn Alcántaraa ${ }^{a}$ Firelys Roa ${ }^{b}, Z^{2}$ imy Díaz ${ }^{c}$ Juan Espinosa ${ }^{d}$ y Luis Feliz
}

Recibido: 26 de julio, 2020 • Aprobado: 12 de septiembre, 2020

Cómo citar: Alcántara E, Roa F, Díaz Z, Espinosa J, Feliz L. Tumor ovárico, células de la granulomatosa juvenil. A propósito de un caso. Hospital Infantil Dr. Robert Reid Cabral (HIRRC), República Dominicana. cysa [Internet]. 9 de junio de 2021 [citado 16 de junio de 2021];5(2):169-76. Disponible en: https://revistas.intec.edu.do/index.php/cisa/article/view/2214

\section{Resumen}

Los tumores ováricos de las células de la granulosa son neoplasias raras, que constituyen solo de $2 \%$ a $5 \%$ de los tumores ováricos. Tienen una incidencia de $1 \mathrm{caso} / 100,000$ mujeres por año. Existen dos subgrupos: la forma adulta y la juvenil. Esta última comprende solamente el $5 \%$ del total de casos y se diagnostica en las primeras tres décadas de la vida, con mediana de 8 a 9 años y se han visto hasta los 30 años. La mayoría de las pacientes se presenta con dolor abdominal localizado, distensión abdominal y masa palpable en pelvis o abdomen. El $10 \%$ de los casos puede debutar con abdomen agudo, debido a ruptura del tumor y hemoperitoneo o por torsión del mismo. La mayoría de las pacientes pre-púberes tienen pubertad precoz isosexual. El tumor es bilateral en $3 \%$ de los casos, generalmente está limitado al ovario al momento del diagnóstico. Suelen responder muy bien a la quimioterapia ${ }^{1,2}$.

Presentamos un caso de una femenina de 5 meses de edad procedente de San José de Ocoa; República Dominicana. La cual presenta historia de aumento progresivo del

\footnotetext{
a Director Servicio de Cirugía Pediátrica. Cirujano Pediatra del Hospital Infantil Dr. Robert Reid Cabral (HIDRRC), Santo Domingo, República Dominicana. Correo-e: drelvynalcantarar@gmail.com

b Coordinadora Residencia de Cirugía Pediátrica. Cirujana Pediatra (HIDRRC). Correo-e: firelysroa@hotmail.com
}

\begin{abstract}
Granulosa cell ovarian tumors are rare neoplasms, accounting for only $2 \%$ to $5 \%$ of ovarian tumors. They have an incidence of 1 case / 100,000 women per year. There are 2 subgroups: the adult form and the juvenile. The latter comprises only $5 \%$ of all cases and is diagnosed in the first 3 decades of life, between 8 to 9 years and has been seen up to 30 years. Most patients present with localized abdominal pain, bloating, and a palpable mass in the pelvis or abdomen. $10 \%$ of cases may debut with an acute abdomen, due to rupture of the tumor and hem peritoneum or due to torsion of the same. Most pre-pubertal patients have isosexual precocious puberty. The tumor is bilateral in 3\% of cases, it is generally limited to the ovary at the time of diagnosis. They tend to respond very well to chemotherapy $^{12}$.

We present a case of a 5-month-old female from San José De Ocoa; Dominican Republic. Which presents a history of progressive increase in breast diameter from the second week of life. The patient was given an external follow-up

\footnotetext{
${ }^{\mathrm{c}}$ Cirujana Pediatra (HIDRRC). Correo-e: zadadiva@gmail.com

d Cirujano Pediatra (HIDRRC). Correo-e: mannyespinosa@hotmail.com

${ }^{\mathrm{e}}$ Residente de Cirugía Pediátrica (HIDRRC).

Correo-e: drluisfeliz@hotmail.com
} 
diámetro mamario desde su segunda semana de vida. A la paciente se le realizó un seguimiento externo en nuestro servicio, donde compaginó la exploración física con un aumento progresivo de la circunferencia abdominal junto con estudios complementarios que evidenciaron líquido libre en la cavidad abdominal.

Palabras clave: tumor ovárico; tumor de células de la granulomatosa; pubertad precoz; tumor maligno del estroma de los cordones sexuale; tumor de células de la granulomatosa juvenil.

\section{Presentación de caso clínico}

\section{Introducción}

Los tumores ováricos de las células de la granulosa son neoplasias raras, que constituyen solo $2 \%$ a $5 \%$ de los tumores ováricos. Tienen una incidencia de 1.5 casos/100,000 mujeres por año. Existen dos subgrupos de acuerdo a su presentación clínica y características histológicas: la forma adulta y la juvenil. Esta última comprende solamente el $5 \%$ del total de casos y se diagnostica en las primeras tres décadas de la vida, con mediana de 8 a 9 años cuando se incluyen solo menores de 16 años, y de 13 a 17 años cuando las series incluyen todas las edades; el $97 \%$ son vistos a los 30 años de edad ${ }^{1,2}$. La mayoría de los pacientes tienen niveles séricos y niveles de estrógeno urinarios elevados, mientras que los niveles de gonadotropina son bajos. Este perfil ayuda a diferenciar a los niños con estos tumores de aquellos con verdadera precocidad sexual, secretores de gonadotropina lesiones o tumores suprarrenales feminizantes. Las hormonas peptídicas inhibina y hormona antimuleriana son producidas por los ovarios en células de la granulosa y pueden ser marcadores tumorales útiles para el diagnóstico y seguimiento de tumores de células granulosas $^{1}$. La mayoría de las pacientes se presenta con dolor abdominal localizado, distensión abdominal y masa palpable en pelvis o abdomen. El 10 $\%$ de los casos puede debutar con abdomen agudo, debido a ruptura del tumor y hemoperitoneo o por to our department, where she combined the physical examination with a progressive increase in the abdominal girth coupled with complementary studies that showed free fluid in the abdominal cavity.

xxxFaltan palasbras clave!

torsión del mismo. La mayoría de las pacientes pre púberes tienen pubertad precoz isosexual, es el signo de presentación en la mayoría de las niñas premenarcales que tienen este tumor, caracterizada por desarrollo prematuro de genitales externos, crecimiento de vello púbico y axilar, secreción vaginal, hemorragia uterina y avanzado edad ósea ${ }^{1,2}$. El tumor es bilateral en $3 \%$ de los casos, generalmente está limitado al ovario al momento del diagnóstico ${ }^{1}$.

La presentación clínica de los tumores de células granulomatosa juvenil muestra un patrón histológico, características y comportamiento biológico muy distintos de la contraparte adulta. La variedad juvenil suele ser relativamente una lesión grande, que promedia $12.5 \mathrm{~cm}$ de diámetro. En laparotomía, aparece como una neoplasia sólida de color amarillo bronceado o gris con áreas quísticas, que a menudo contienen líquido hemorrágico. A diferencia de los tumores adultos, el tipo juvenil tiene abundante citoplasma eosinofílico o luteinizado con núcleos atípicos y una tasa mitótica más alta de contenido de ácido desoxirribonucleico y la cinética del ciclo celular analizada por Citometría de flujo no necesariamente se correlacionan con el pronóstico en niños, ya que a menudo lo hacen en adultos $^{1}$.

En los niños, estos tumores están asociados con un pronóstico favorable, porque en más del $90 \%$ de niños afectados la enfermedad se encuentra en estadio I. La supervivencia de los pacientes con 
estadio FIGO (tabla 1); IA fue del $100 \%$, el estadio IC fue del $76 \%$ y el estadio II / III fue del $67 \%{ }^{1}$

\section{Materiales y métodos}

Descripción de un caso clínico y revisión de la literatura.

Tabla 1. Estatificación del carcinoma de ovario: Federación Internacional de Ginecología y Obstetricia. (FIGO)

\begin{tabular}{|c|l|}
\hline \multicolumn{2}{|c|}{ Estatificación del carcinoma de ovario: Federación Internacional de } \\
Ginecología y Obstetricia. (FIGO)
\end{tabular}

\section{Reporte de caso}

Presentamos un caso de paciente femenina de 5 meses de edad, procedente de San José de Ocoa, República Dominicana. La cual presenta aumento del perímetro abdominal secundario a líquido libre en cavidad, concomitante a aumento progresivo del diámetro mamario desde su segunda semana de vida. La paciente fue referida por endocrinología para seguimiento de forma externa en nuestro departamento, donde se le realizaron estudios complementarios. Se le realiza sonografía pélvica, donde se evidencia masa a expensa en ovario izquierdo, líquido libre sin aspecto grumoso, de cantidad moderada; útero aumentado de tamaño con paredes engrosadas. Se considera presencia ante pubertad precoz. Estadísticamente a correlacionar con lesión de células germinales (las afecciones ginecológicas malignas representan aproximadamente el $2 \%$ de todos los tipos de cáncer en los niños y del $60 \%$ al $70 \%$ de estas lesiones surgen en el ovario ${ }^{1}$ ) a excluir teratoma, lesión de la granulomatosa, tumor de células germinales tipo Leidy y Germinoma.

Al ser evaluada la paciente está alerta, activa, afebril, hidratada, eupneico; en condiciones generales estables.

$\mathrm{Al}$ examen físico (figura 1) presenta mamas aumentadas de tamaño de forma bilateral, onda ascítica abdominal; masa a nivel inguinal que protruye a nivel izquierdo y que reduce de forma espontánea. Genitales con labios mayores aumentados de tamańo, secreción blanquecina vaginal. 


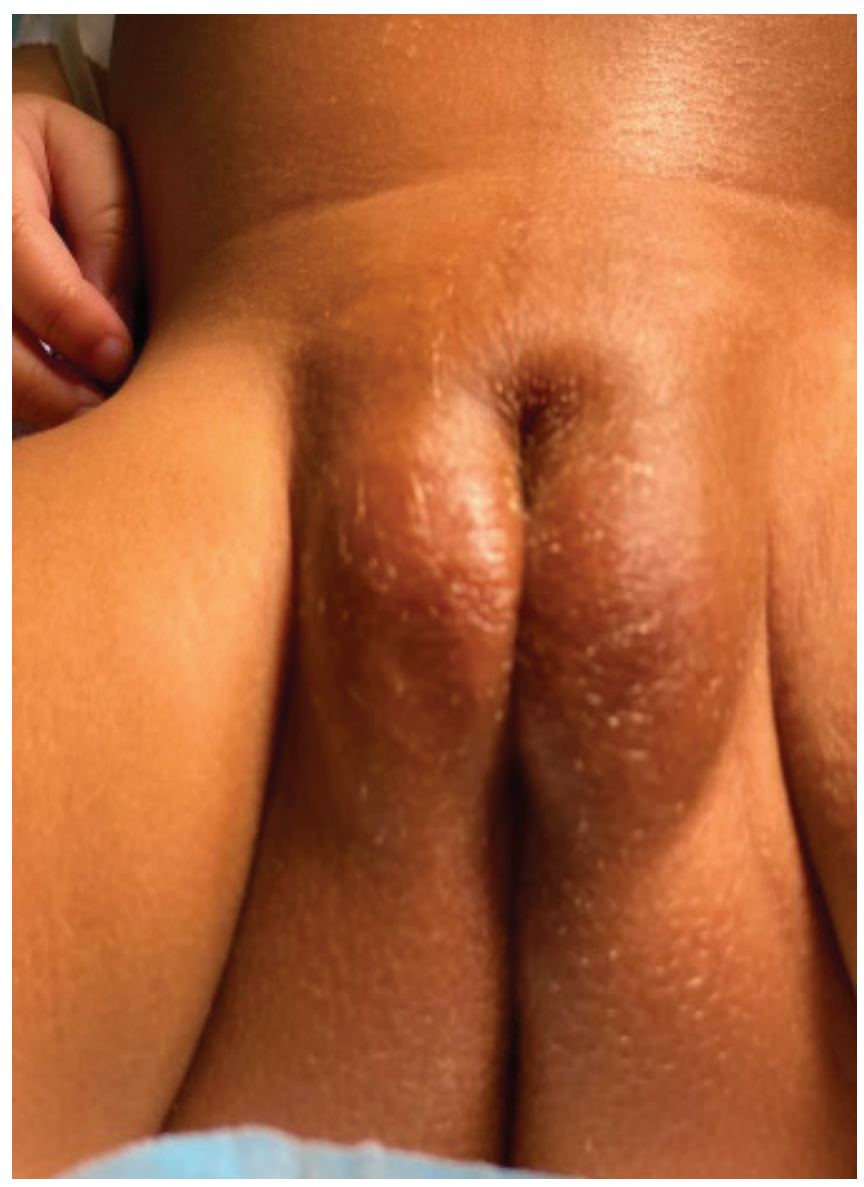

\section{Analítica pre quirúrgica:}

\begin{tabular}{|c|c|}
\hline Alfa feto proteína & $29.40 \mathrm{ng} / \mathrm{ml}$ \\
\hline $\begin{array}{c}\text { Gonadotropina corió- } \\
\text { nica cuantitativa }\end{array}$ & $<0.200 \mathrm{mIU} / \mathrm{ml}$ \\
\hline TSH & $2.36 \mathrm{UI} / \mathrm{ml}$ \\
\hline T3 & $2.51 \mathrm{ng} / \mathrm{ml}$ \\
\hline T4 & $11.68 \mathrm{ug} / \mathrm{dl}$ \\
\hline Fosfatasa alcalina & $182 \mathrm{U} / \mathrm{L}$ \\
\hline LDH & $282 \mathrm{U} / \mathrm{L}$ \\
\hline Androstenediona & $1.34 \mathrm{ng} / \mathrm{ml}$ \\
\hline Estradiol & $2,407 \mathrm{pg} / \mathrm{ml}$ \\
\hline Estrógenos & $1,000 \mathrm{pg} / \mathrm{ml}$ \\
\hline FSH & $<0.3 \mathrm{Mui} / \mathrm{ml}$ \\
\hline LH & $<0.3 \mathrm{Mui} / \mathrm{ml}$ \\
\hline Prolactina & $59.5 \mathrm{ng} / \mathrm{ml}$ \\
\hline Testosterona & $0.03 \mathrm{ng} / \mathrm{ml}$ \\
\hline TSH & $3.05 \mathrm{UI} / \mathrm{ml}$ \\
\hline T4 Libre & $1.37 \mathrm{ng} / \mathrm{dl}$ \\
\hline
\end{tabular}
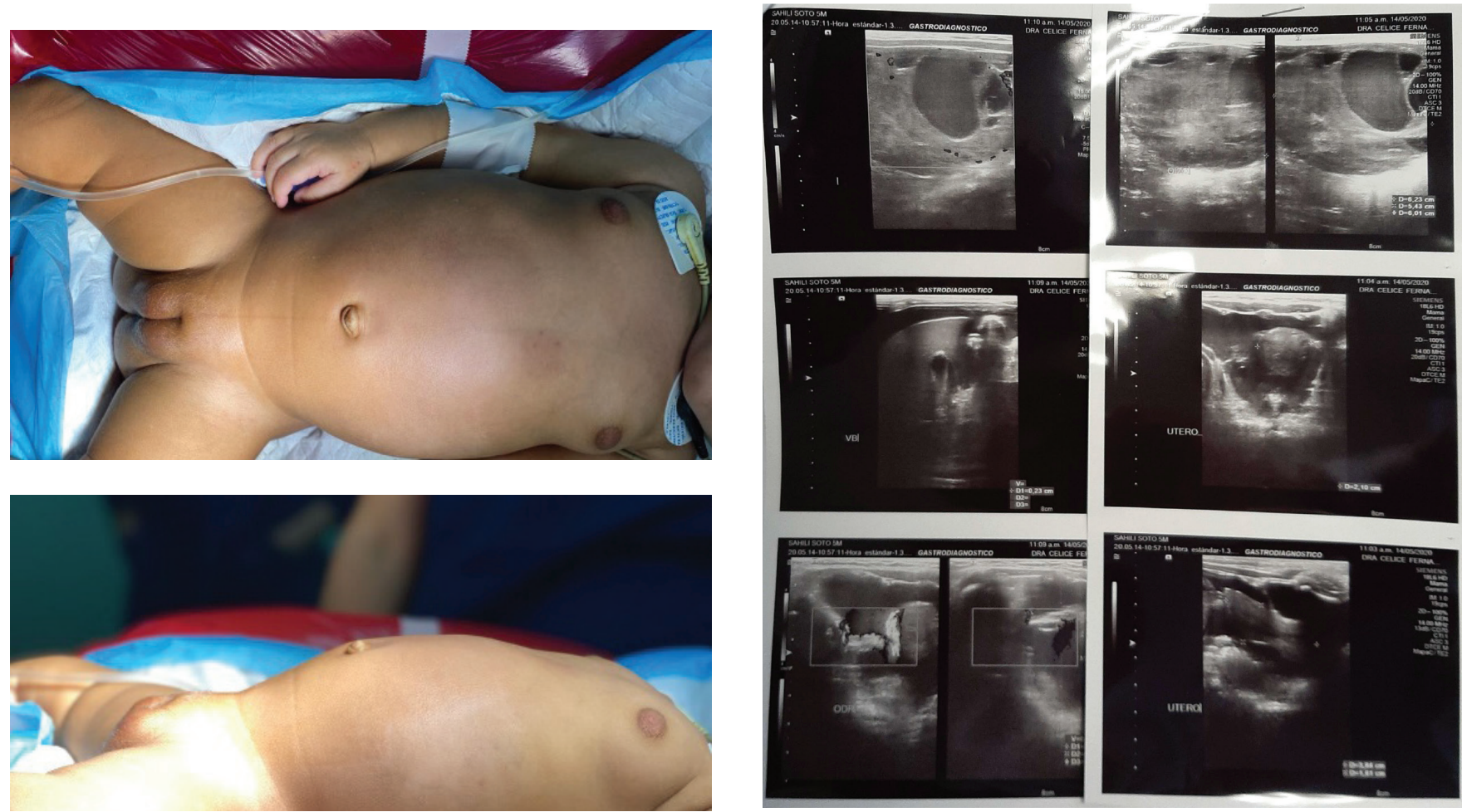

Figura 1. Imágenes de la paciente

Figura 2. Sonografía Abdomino-pélvica 
1. Masa en ovario izquierdo estadísticamente a correlacionar con lesión de células germinales a excluir teratoma.

2. Útero aumentado de tamaño para la edad con evidencia de estímulo hormonal.

\section{Ascitis.}

Tras valorar presencia de masa ovárica, la paciente se ingresa en quirófano para exéresis y biopsia del área afectada. Entre los hallazgos se evidencia masa a nivel de ovario izquierdo (figura 3) por lo que se realiza Salpingo-ooforectomía izquierda por compromiso del anexo izquierdo, de igual manera se observan a nivel de la placa de Petri, áreas blanquecinas vacuoladas contenidas por capa superficial, aunado a nivel del ovario. A nivel del epiplón con forma engrosada y vasos ingurgitados; donde se consideran exéresis así como posterior realización de herniorrafia izquierda.
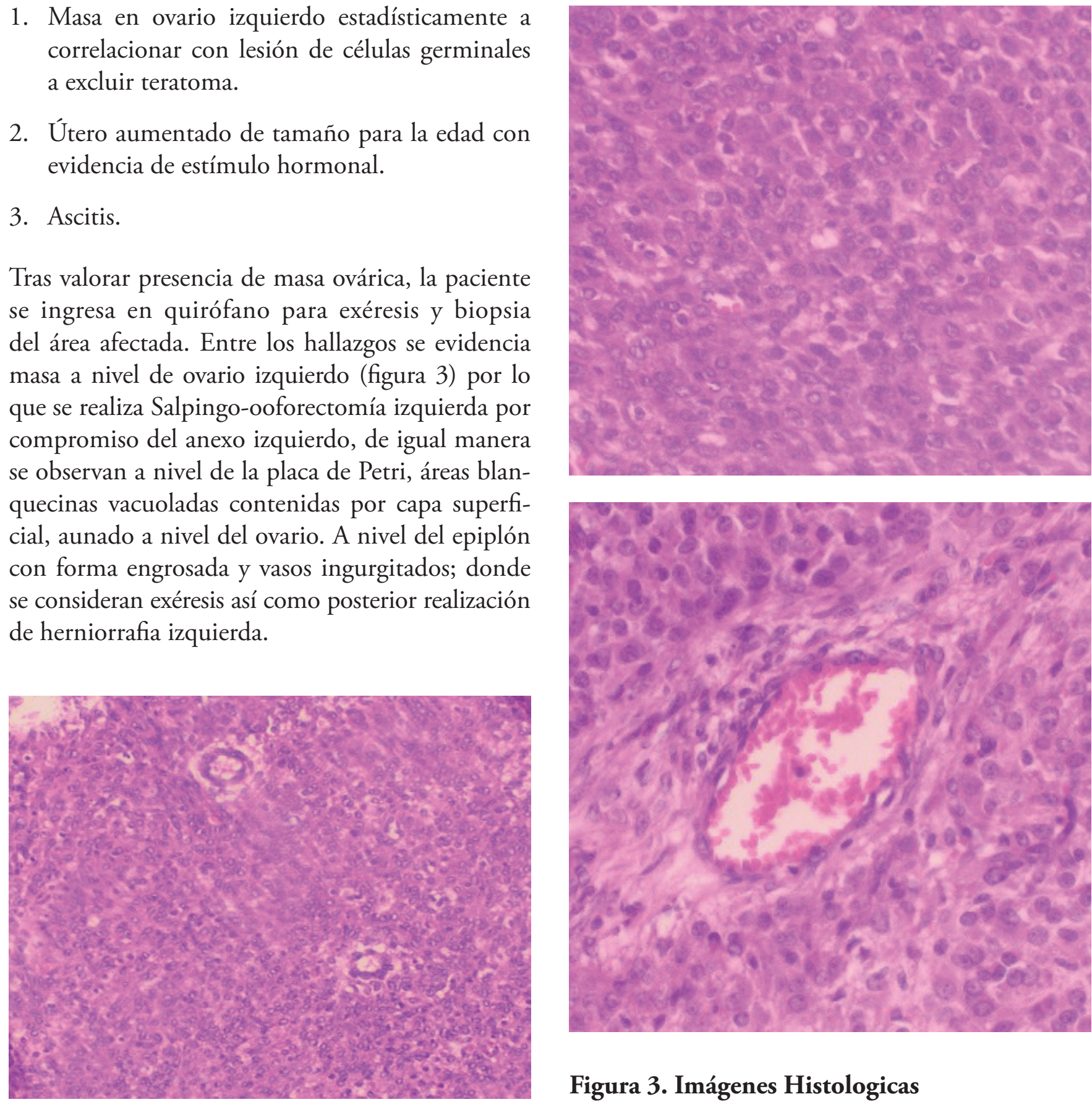

Figura 3. Imágenes Histologicas 


\section{Reporte anato-patológico}
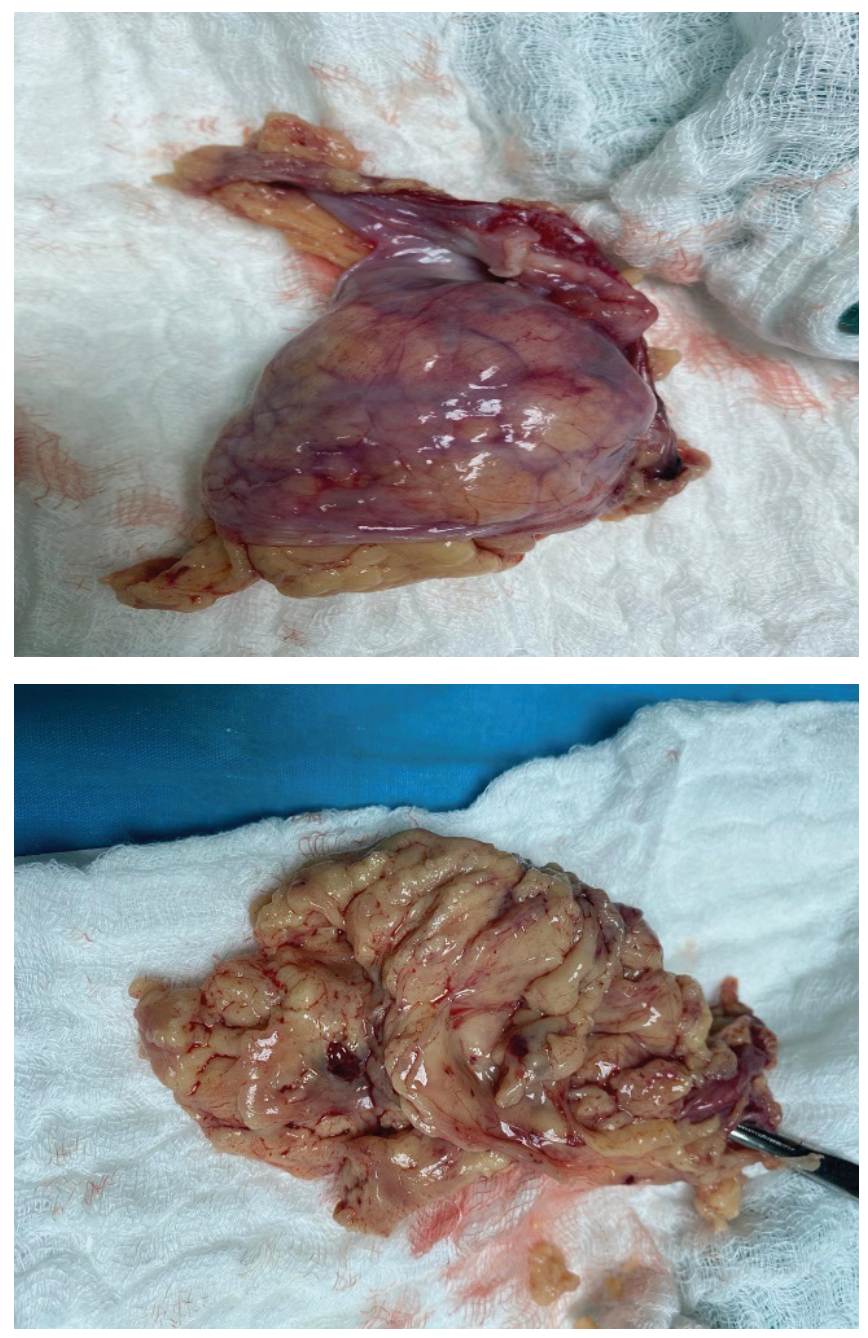

Figura 4. Tumor de células de la granulomatosa infantil

\section{Analíticas postquirúrgico:}

\begin{tabular}{|c|c|}
\hline Leucocitos & 6.8 \\
\hline Granulocitos & 71.1 \\
\hline Linfocitos & 25.4 \\
\hline $\begin{array}{c}\text { Hemoglo- } \\
\text { bina }\end{array}$ & 10.9 \\
\hline Hematocrito & 31.8 \\
\hline Plaquetas & 335 \\
\hline
\end{tabular}

Posteriormente, la paciente fue evaluada por el departamento de Endocrinología, donde orientaron a la madre e indicaron pruebas hormonales control en dos semanas y el inicio de tratamiento con quimioterapia (posterior al reporte patológico).

\section{Discusión}

Los tumores de las células de la granulosa juvenil son tumores del estroma gonadal, que se presentan más frecuentemente en niñas, adolescentes y adultas jóvenes, representando aproximadamente el $10 \%$ de todas las neoplasias del ovario en niñas ${ }^{1}$. Los tumores del estroma y de los cordones sexuales representan aproximadamente $5 \%$ de las neoplasias de ovario en el paciente pediátrico, debido a que estas células participan en la función ovárica hormonal. La mayoría de los tumores del estroma o de los cordones sexuales son capaces de secretar hormonas (estrógenos, andrógenos y corticoides), lo cual explica la pubertad precoz asociada con estos tipos de cáncer. Estos tumores típicamente se detectan en etapas tempranas y pueden recurrir hasta 30 ańos después del tratamiento inicial ${ }^{1,2}$.

Cuando la variante juvenil se presenta antes de la pubertad, se acompaña de manifestaciones de pubertad precoz, además de los signos y síntomas asociados al crecimiento del tumor. Se caracteriza por crecimiento lento e indolente, dando lugar a tumores de gran tamaño al momento del diagnóstico ${ }^{2}$.

Realizar un diagnóstico diferencial en edades jóvenes, se asocia con la encondromatosis, el síndrome de Peutz Jeghers y el síndrome de Maffuci ${ }^{1,3}$.

El estadio es el factor pronóstico que se relaciona en forma inequívoca con recurrencia, donde a mayor estatificación mayor será la recurrencia ${ }^{1,2}$. Otros factores pronósticos que se mencionan como significativos son la ruptura del tumor, aunque según las series los resultados son variables ${ }^{2}$. Los tumores recidivantes muestran un alto grado de actividad mitótica, entonces, el alto índice mitótico del tumor 
es proporcional a una próxima recaída y se asocia a estatificaciones altas, así como a la mortalidad ${ }^{4,5}$. Los pacientes que reciben quimioterapia junto a la exéresis del tumor abdominal o con terapia adyuvante presentan mejores pronósticos y baja recurrencia, si se realiza una cita programada de recurrencia. Los tumores rotos con ascitis serosa, y que se presenten bilaterales, no fueron tratados después de la cirugía, presentan mayor grado de recurrencia así como de mortalidad. Por eso deseamos enfatizar la importancia del análisis citológico ascítico en la evaluación de la extensión de la enfermedad ${ }^{6}$.

Por esta razón, el índice mitótico puede ser un factor pronóstico valioso; y de esta forma también la actividad oocítica de PI3K transforma las células de la granulomatosa. La resección tumoral completa siempre debe intentarse, ya que la enfermedad tumoral residual se asocia con un mal pronóstico y es mayor al expresar el gen P53, 8, .

\section{Conclusión}

Ante el dato de pubertad precoz se debe considerar la posibilidad de una causa neoplásica, ya que secretan hormonas sexuales o gonadotropinas, como en el caso de los tumores de células de la granulosa variedad juvenil. Como estudio de diagnóstico precoz, se propone el ultrasonido como primera opción, valores hormonales y la tomografía computarizada, que es lo suficientemente sensible para la identificación de tumores intrapélvicos gonadales.

Las intervenciones quirúrgicas se utilizan para la estatificación, la confirmación histológica y en cirugía cito reductora. A menudo, el tratamiento inicial consiste en una histerectomía abdominal total y una Salpingo-ooforectomía bilateral. A las pacientes con la enfermedad localizada se les ofrece procedimientos quirúrgicos que preserven la fertilidad. En ausencia de infiltración significativa, en niñas se intenta preservar el útero junto con el ovario y la trompa contralateral. A las pacientes con tumores avanzados se les administra quimioterapia postquirúrgica.

La cirugía de preservación de la fertilidad es y debe ser el tratamiento de elección para el tumor de células de la granulosa juvenil ovárica; su pronóstico general es bueno.

\section{Financiación}

No hemos recibido financiación para la realización del manuscrito.

\section{Conflicto de intereses}

Ninguno de los autores presenta conflicto de intereses.

\section{Referencias}

1. Jaimes-GarcíaY, Hernández-Pliego G, Sadowinski-Pine S, Palomo-Colli MÁ, Juárez-Villegas L, Cortés-Sauza J. Tumor de células de la granulosa juvenil del ovario asociado a síndrome de Maffucci. Gac mex oncol. 2013;12(3):196-200.

2. Coran, AG. Pediatric Surgery. Ovarian Tumors. D Von Allmen \& ME. Fallat. Cap 39. p. 529-548. 7th edition (C) Elsevier Saunders; 2010.

3. INSERM US14. Orphanet: Tumor maligno del estroma de los cordones sexuales de los ovarios [Internet]. Orpha.net. [cited 2021 Apr 30]. Available from: https://www.orpha.net/consor/ cgi-bin/OC_Exp.php?Expert=35808\&lng=ES

4. Schneider DT, Calaminus G, Wessalowski R, Pathmanathan R, Harms D, Göbel U. Therapy of advanced ovarian juvenile granulosa cell tumors. Klin Padiatr. 2002;214(4):173-8.

5. Young RH, Dickersin GR, Scully RE. Juvenile granulosa cell tumor of the ovary. A clinicopathological analysis of 125 cases. Am J Surg Pathol. 1984;8(8):575-96. 
6. Vassal G, Flamant F, Caillaud JM, Demeocq F, Nihoul-Fekete C, Lemerle J. Juvenile granulosa cell tumor of the ovary in children: a clinical study of 15 cases. J Clin Oncol. 1988;6(6):990-5.

7. Rodríguez ÁLP, Consuegra NM, Kuttothara AJ, Serrano A. Tumor de células de la granulosa. Factores de pronóstico adverso en un tumor infrecuente del ovario [Internet]. Medigraphic.com. [cited 2021 Apr 30]. Available from: https://www.medigraphic.com/pdfs/abc/ bc-2009/bc092j.pdf
8. Kim S-Y, Ebbert K, Cordeiro MH, Romero MM, Whelan KA, Suarez AA, et al. Constitutive activation of $\mathrm{PI} 3 \mathrm{~K}$ in oocyte induces ovarian granulosa cell tumors. Cancer Res. 2016; 76(13):3851-61.

9. Sánchez Jiménez J, Gómez Ángel D, Galera Ruiz H. Valor pronóstico del parámetro inmunohistoquímico p53 en los estadios I y II del carcinoma epidermoide de lengua móvil. Rev esp cir oral maxilofac. 2003;25(5):280-7. 